\title{
EVALUATION OF POSTERIOR FIXED FUNCTIONAL SPACE MAINTAINERS MADE OF FIBER REINFORCED COMPOSITE: AN IN VITRO STUDY
}

\author{
Yassa $\mathrm{MK}^{*}$ and $\mathrm{Khattab} \mathrm{NM}^{* *}$
}

\begin{abstract}
Background: Fiber-reinforced composite (FRC) space maintainer is proving to give solutions for the limitations encountered with the conventional band and loop space maintainer. However, the longevity of FRC is a controversial aspect.

Aim of the study: Evaluation of the reinforcing effects of glass fibers on the flexural strength of composite resin.

Materials and Methods: Three groups of specimens were prepared using a white Teflon split mold; a control group of composite resin bars, one glass fiber reinforced composite bars and two glass fiber reinforced composite bars. Mean flexural strength values in mega Pascal (MPa) were determined in a 3-point bending test.

Results: A significant difference in mean flexural strength between the three groups was found.

Conclusions: Flexural strength of composite resins improved with incorporation of glass fibers, and increasing fiber volume led to substantial improvement in the flexural strength.
\end{abstract}

KEY WORDS: Fiber reinforced composite, chair-side, direct, functional, esthetic space maintainer.

\section{INTRODUCTION}

A healthy and well-functioning dentition is important during all stages of life since it supports essential human functions such as speaking, socializing and eating. Teeth help to give the face its individual shape and form. Healthy primary teeth maintain the space for their permanent successors, developing in the jaw underneath, until they are ready to erupt (FDI, 2015).

Premature loss of primary teeth may harm the normal occlusion development. Drifting of adjacent primary and permanent teeth into the available space created by the premature tooth loss may compromise the eruption of the succedaneous

* Assistant lecturer in Pediatric and Community Dentistry Department, Faculty of Dentistry, Minia University.

** Professor in Pediatric and Community Dentistry Department, Faculty of Dentistry, Minia University. 
teeth. Insertion of space maintainers to preserve arch length can prevent or limit the malocclusion development (Law, 2013).

Clinicians may advise various types of space maintainers. Among them, band and loop (B\&L) is the most commonly used fixed space maintainer (Setia et al., 2014).

Band and loop appliances are well tolerated and durable, however, they have the following limitations; they do not restore normal function, incorporate esthetic concern or prevent rotation and tipping of abutment teeth. In addition, they require clinical and laboratory steps for their fabrication and at least annual removal and fluoride application. Moreover, they have the tendency for disintegration of the cement which is the most commonly reported reason for failure (Srivastava et al., 2016).

These limitations of band and loop space maintainers encourage the search for newer materials and designs of the appliances. (Setia et al., 2013; Garg et al., 2014).

Fiber-reinforced composite (FRC) technology could provide solutions for such limitations. The current in vitro study was conducted to evaluate the reinforcing effects of glass fiber on the flexural strength of composite resin space maintainer replacing a missing primary molar, to support their clinical use as an alternative for conventional appliances.

\section{MATERIALS AND METHODS}

Mean flexural strength values $\left(\sigma_{f}\right)$ in mega Pascal (MPa) were determined for FRC resin bars compared to an unreinforced control group (bars of composite resin only).

Equal sized rectangular bar shaped specimens with dimensions similar to that of the clinical situation $(16 \times 5 \times 4 \mathrm{~mm})$ were prepared for testing (Figure 1).

Three groups of specimens were prepared, each group included five specimens; group (1) was the control one without fiber incorporation, group (2) was FRC bars with one fiber only and group (3) was FRC bars containing two fibers in each bar.

Control group specimens were prepared by condensing the composite (G-aenial Posterior, GC DENTAL PRODUCTS CORPOR., Japan) into a white polytetrafluoroethylene (Teflon) split mold against a microscope glass slab, with a Mylar strip between the glass slab and the Teflon mold. A second Mylar strip and glass slab were stabilized in contact with the uncured composite and pressed to the thickness of the mold. The split molds were held together by an adjustable metal frame.

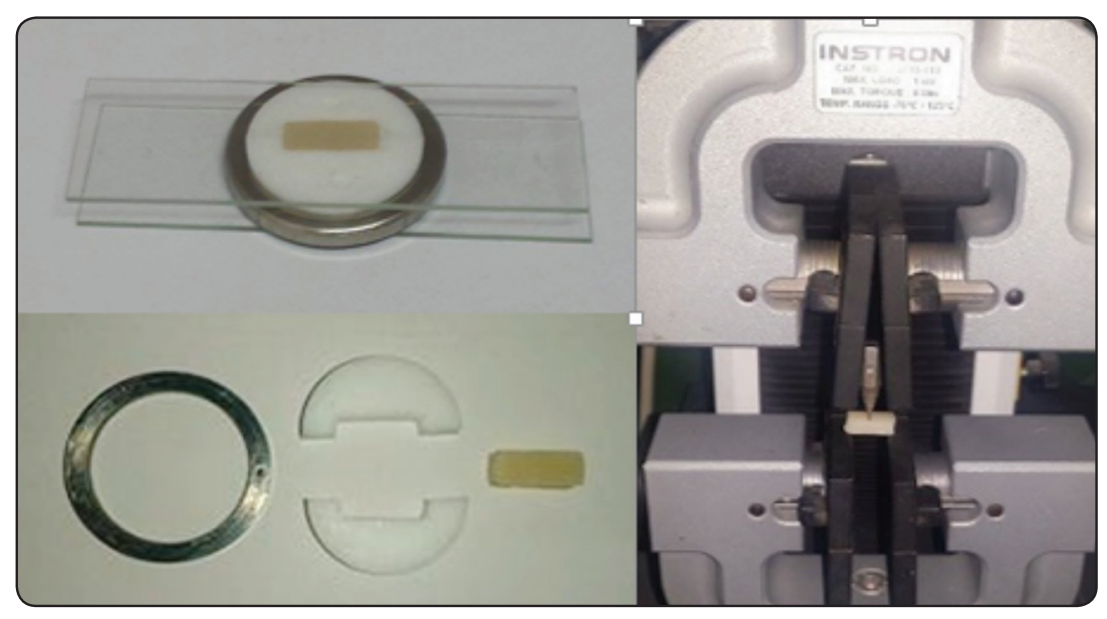

Fig. (1) Preparation and testing of the specimens. 
FRC beams (group 2) were prepared in the same mold where $1 \mathrm{~mm}$ of the same composite resin was condensed followed by one fiber (everStick ${ }^{\circledR} \mathrm{C} \& \mathrm{~B}$, GC DENTAL PRODUCTS CORPOR., Japan) placement longitudinally through the whole length in the base (tensile side) of the specimen preparation mold that was covered again by composite resin. Group 3 specimen were prepared as group 2 but two fiber were incorporated in each specimen.

The test specimens were polymerized with the Radii Plus LED curing light (SDI limited, Australia) for 20 seconds from both sides.

Mean flexural strength values were determined in a 3-point bend test using an Instron Universal Testing Machine (Instron, Corporation, Canton, MA, USA) with a crosshead speed of $1 \mathrm{~mm} / \mathrm{min}$ and the load-deflection curves were recorded with a Bluehill Lite computer software. Differences in means were compared to test the influence of fiber reinforcement with Mann-Whitney test.

\section{RESULTS}

Mean flexural strength (M Pa) was $97.817 \pm 6.003$ for the control group (composite resin only) while increased to $132.234 \pm 11.354$ for the 1 fiber reinforced composite group, and scored $184.089 \pm 9.130$ for the 2 fibers reinforced composite group. The differences between the three groups were statistically significant $(\mathrm{P}<0.05)$ (Figure 2).

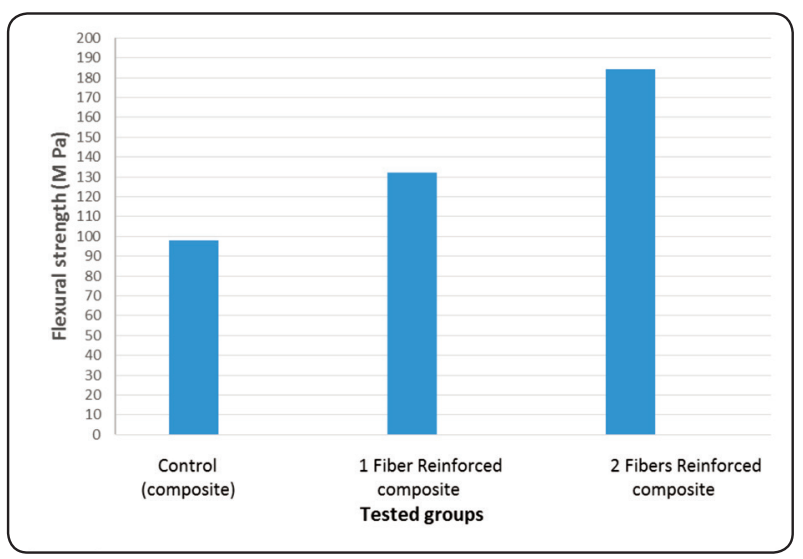

Fig. (2) Mean flexural strengths for the three tested groups

\section{DISCUSSION}

Premature loss of primary teeth continues to be a common problem in pediatric dentistry, resulting in disruption of arch integrity and adversely affecting the proper alignment of permanent successors (Srivastava et al., 2016). Immediate provision of a space maintainer is the safest way to eliminate or reduce some of these difficulties (Law, 2013).

Today, fiber reinforcement is a proven technology which is being in almost every field. In dentistry, FRC materials are gaining popularity. An important feature of composite is its ability to be tailored until it meets the design requirements. Although composite resin experience a considerable mechanical challenge during function, fiber incorporation resulted in the development of improved dental composites with high mechanical properties extending its dental applications (Van Heumen et al., 2008).

FRC was selected as space maintainer material as they possess the advantages of being easily manipulated and directly chair-side applied. Moreover, they are fixed, minimally invasive, aesthetic, readily repaired, reversible, biocompatible, and of relatively lower treatment costs (Mocanu et al., 2012). Since the longevity of FRC is a controversial issue, this study aimed to measure the flexural strength of the appliances.

Flexural strength is a meaningful mechanical property for brittle materials to predict their clinical performance (Muench et al., 2005 and Spyrides et al., 2015). The three-point bending test is a simple method - both in specimen fabrication and load application - to determine flexural strength. The test is widely used in dental research as stress distribution in this test is similar to the stress distribution in fixed bridges (Gundogdu et al., 2014).

A standard three-point bending test has been published by the International Standards Organization (ISO 4049). It describes the preparation of a test specimen and the use of a universal test apparatus for bending tests on composite beams. 
Yap and Teoh (2003) recommended the use of specimens with clinically realistic dimensions for flexural test. The use of specimens with lower dimensions can lead to flexural strength values similar to the ones obtained with standardized specimen (ISO 4049), with the advantage of demanding less amount of material and being less time consuming (Muench et al., 2005).

In this study, dimensions of specimen were similar to the clinical situation; shorter than standard and the cross section was greater according to manufacturer instructions that indicated 1 to $2 \mathrm{~mm}$ of composite covering the fibers.

Glass fibers were chosen for composite reinforcement as they are considered the fibers of choice in dental applications because of the good esthetic and superior mechanical properties as well as their ability to chemically bond to dental composite resin materials (Tayab et al., 2015).

The selected type of glass fibers is contained within a bi-phase matrix consisting of dimethacrylate and poly methyl methacrylate polymers. The PMMA matrix is highly viscous compared to the dimethacrylate system, hence improving both the handling properties and bonding properties of the fibers (Saridag et al., 2012).

Specimens were prepared in split mold held together by a metal frame to produce equal sized specimens and easily bring these specimens out. Composite was condensed into the split mold against a microscope glass slab to provide flat specimens with uniform surface (Sabatini, 2013).

Fibers were oriented in a longitudinal direction (along the axis of the test specimens) because longitudinal fibers exhibit superior mechanical properties along their long axes to resist predominant oral stresses. Moreover, fibers were placed at the tensile side of the bar as it is the most efficient location for reinforcement (van Heumen et al., 2008).
The results of the current study showed that there was a statistically significant difference in flexural strength between the FRC groups and the control group (composite resin). This result was similar to those reported by Ellakwa et al. (2001); Lassila and Vallittu (2004); Mosharraf and Givechian (2012); Fonseca et al. (2014); Gundogdu et al. (2014); and Caixeta et al. (2015). This finding could be explained on the basis that fibers improve mechanical properties of composite resin by acting as crack stoppers (Butterworth et al., 2003).

The flexural strength of composite resin specimens reinforced with two fibers surpassed that of the group reinforced with one fiber and the difference was also statistically significant. These results goes in accordance with van Heumen et al. (2008); Abdulmajeed et al. (2011) and Fonseca et al. (2014) who disclosed that increasing fiber volume resulted in improvement of mechanical properties of composite resin.

The current study revealed that the mean flexural strength of the specimens reinforced with one fiber is around the normal occlusal forces (354.01 \pm 134.04 newton) reported by Takaki et al. (2014), while the flexural strength of the group reinforced with 2 fibers is much higher.

Within the limitations of the present study, it can be concluded that:

1- Flexural strength of composite resins did improved with incorporation of glass fibers.

2- Increasing fiber volume led to substantial improvement in the flexural strength.

\section{REFERENCES}

- $\quad$ Butterworth C, Ellakwa AE, Shortall A: Fibre-reinforced composites in restorative dentistry. Dent Update. 2003; 30(6):300-306.

- Caixeta RV, Guiraldo RD, Berger SB, Kaneshima EN, Júnior EM, Drumond AC, Júnior AG, Lopes MB: Influence of glass-fiber reinforcement on the flexural strength of different resin composites. Appl Adhes Sci. $2015 ; 3(24): 1-6$ 
- Ellakwa AE, Shortall AC, Marquis PM, Shehata: The influence of fibre placement and position on the efficiency of reinforcement of fibre reinforced composite bridgework. J Oral Rehabil 2001; 28(8): 785-791.

- $\quad$ FDI World Dental Federation: The Challenge of Oral Disease - A call for global action. The Oral Health Atlas. 2nd ed. Geneva; 2015, PP 9-10

- Fonseca RB, Marques AS, Bernades Kde O, Carlo HL, Naves LZ: Effect of glass fiber incorporation on flexural properties of experimental composites. Biomed Res Int. 2014; 2014:542678.

- $\quad$ Garg A, Samadi F, Jaiswal JN, Saha S: 'Metal to resin': a comparative evaluation of conventional band and loop space maintainer with the fiber reinforced composite resin space maintainer in children. J Indian Soc Pedod Prev Dent. 2014; 32(2):111-116.

- Gundogdu M, Kurklu D, Yanikoglu N, Kul E: The Evaluation of Flexural Strength of Composite Resin Materials with and without Fiber. Dentistry 2014; 4(9): $1-6$.

- International Organization for Standardization (ISO 4049): Dentistry - Polymer-based restorative materials 4th ed. 2009; PP: 1-28.

- Lassila LV, Vallittu PK: The effect of fiber position and polymerization condition on the flexural properties of fiber-reinforced composite. J Contemp Dent Pract 2004; 5(2): 14-26.

- Law CS: Management of premature primary tooth loss in the child patient. CDA journal 2013; 41(8):612-618

- Mocanu RM, Țănculescu O, Ifteni G, Andronache M, Apostu A, Iordache C, Mârţu S: Possibilities and limits of fiber reinforced composites in fixed prosthodontics. Romanian Journal of Oral Rehabilitation, 2012; 4(3): 74-77.

- Mosharraf R, Givechian P: Effect of fiber position and orientation on flexural strength of fiber-reinforced composite. JIDAI 2012; 24(1): 21-27.
- Muench A, Correa IC, Grande RH, João M: The effect of specimen dimensions on the flexural strength of a composite resin. J Appl Oral Sci. 2005; 13(3):265-8.

- $\quad$ Sabatini C: Comparative study of surface microhardness of methacrylate-based composite resins polymerized with light-emitting diodes and halogen. Eur J Dent. 2013; 7(3): 327-335.

- $\quad$ Saridag S, Ozyesil AG, Pekkan G: Fracture strength and bending of all-ceramic and fiber-reinforced composites in inlay-retained fixed partial dentures. Journal of Dental Sciences 2012; 7: 159-164.

- $\quad$ Setia V, Pandit IK, Srivastava N, Gugnani N, Gupta M: Banded vs Bonded Space Maintainers: Finding Better Way Out. Int J Clin Pediatr Dent. 2014; 7(2): 97-104.

- Setia V, Pandit IK, Srivastava N, Gugnani N, Sekhon HK: Space Maintainers in Dentistry: Past to Present. J Clin Diagn Res. 2013; 7(10): 2402-2405.

- $\quad$ Spyrides SM, Prado Md, Simão RA, Bastian FL: Effect of Plasma and Fiber Position on Flexural Properties of a Polyethylene Fiber-Reinforced Composite. Braz Dent J. 2015; 26(5):490-496.

- Srivastava N, Grover J, Panthri P: Space Maintenance with an Innovative "Tube and Loop" Space Maintainer (Nikhil Appliance). Int J Clin Pediatr Dent. 2016; 9(1):86-89.

- Takaki P, Vieira M, Bommarito S: Maximum Bite Force Analysis in Different Age Groups. Int. Arch. Otorhinolaryngol. 2014; 18(3): 272-276.

- Tayab T, Shetty A, Kayalvizhi G: The Clinical Applications of Fiber Reinforced Composites in all Specialties of Dentistry an Overview. International Journal of Composite Materials. 2015; 5(1): 18-24.

- $\quad$ van Heumen CC, Kreulen CM , Bronkhorst EM , Lesaffre E, Creugers NH: Fiber-reinforced dental composites in beam testing. Dental Materials 2008; 24: 1435-1443.

- Yap AU, Teoh SH: Comparison of flexural properties of composite restoratives using the ISO and mini-flexural tests. J Oral Rehabil. 2003; 30(2):171-7. 